\title{
De bacharel a professor: reflexões a partir do desenvolvimento profissional docente
}

Este ensaio aborda a temática da formação contínua de professores no ensino superior para o profissional bacharel quando este adentra os espaços acadêmicos sem preparo pedagógico para o exercício da docência. Nessa direção, os diálogos teóricos acerca da formação de professores trazem como objetivo a necessidade de refletir os principais aspectos relativos ao papel profissional docente como também a importância do movimento de ação-reflexão-ação como pressuposto dessa atividade. A abordagem teórica está nos recentes estudos sobre a formação de professores em docência no ensino superior. Espera-se, contudo, que as ações político-institucionais dos sistemas de ensino universitário elaborem e coloquem em prática, programas de desenvolvimento profissional para seu corpo de professores da mesma forma que a autoformação também se faça presente como resultante do processo reflexivo em que tenha o bacharel professor, consciência de seu papel invasivo na função docente que agora assume.

Palavras-chave: Formação de Professores; Docência Universitária; Professor Reflexivo; Autoformação; Pedagogia Universitária.

\section{From bachelor to teacher: reflections from the teaching professional development}

This essay addresses the theme of continuing teacher education in higher education for the bachelor professional when he enters the academic spaces without pedagogical preparation for the exercise of teaching. In this sense, the theoretical dialogues about teacher education bring as objective the need to reflect the main aspects related to the professional teaching role as well as the importance of the action-reflection-action movement as a presupposition of this activity. The theoretical approach is found in recent studies on teacher education in higher education. However, the political-institutional actions of university education systems are expected to develop and implement professional development programs for their faculty in the same way that self-training is also present as a result of the reflective process in which the bachelor teacher, aware of his invasive role in the teaching role he now assumes.

Keywords: Teacher training; University teaching; Reflective teacher; Self-training; University Pedagogy.

Topic: Formação e Qualificação do Professor

Reviewed anonymously in the process of blind peer.
Received: 20/12/2017

Approved: 16/03/2018
Gean Breda Queiros (iD)

Faculdade São Gabriel da Palha, Brasil

http://lattes.cnpq.br/9520588940694258

http://orcid.org/0000-0003-0242-773X

geanbreda@hotmail.com

\section{Referencing this:}

QUEIROS, G. B.. De bacharel a professor: reflexões a partir do desenvolvimento profissional docente. Educationis, v.6, n.1, p.1-12, 2018. DOI: http://doi.org/10.6008/CBPC2318-3047.2018.001.0001 


\section{INTRODUÇÃO}

Como se forma um professor universitário? Observamos que esse assunto vem crescendo de forma exponencial no campo de pesquisas acadêmicas pelo fato das mudanças impostas neste novo século, principalmente sobre os processos de ensino-aprendizagem por quais os professores são desafiados a se reinventarem diariamente. Mudanças educacionais ao longo do século XX levaram a uma necessidade de repensar os aspectos formativos dos professores (FRAGELLI et al., 2014).

O contexto universitário do século XX e XXI é pautado no tripé educacional: pesquisa, ensino e extensão, sendo que seus docentes tem a necessidade de articular esses três segmentos de maneira colaborativa. Porém, diversos aspectos institucionais que circundam o ensino superior tais como: o excesso de burocracias, a necessidade de financiamentos externos as universidades provenientes das agências fomentadoras devido ao baixo incentivo do Estado e avaliações de qualidade pautadas no pressuposto da produtividade, conduziram os docentes a focarem mais nas atividades vinculadas as pesquisas em detrimento de outros aspectos igualmente importantes na profissionalidade docente.

Historicamente, Gonçalves et al. (2002) apresenta que a formação do professor universitário se dava por meio do autodidatismo, onde não havia cursos e nem instituições formadoras de professores. Destacamos que ao exigir conhecimento e dedicação para atuar na área acadêmica, a formação do docente universitário, traz desafios que devem ser superados por eles e pelas Instituições de Ensino Superior na oferta de formação específica no campo pedagógico, incluindo a didática.

A necessidade e importância da formação docente universitária também se fazem, pela complexidade do seu trabalho, haja vista que este participa diretamente na formação de novos profissionais. É necessário, em geral, que o professor tenha experiência profissional e didático-pedagógica, incluindo, em alguns casos, alguma especialização e títulos de mestre ou doutor.

Coadunamos com a afirmação de Pimenta et al. (2014), onde entendemos que ao considerarmos a trajetória acadêmica dos professores em seus processos e meios de formação em nível superior, é necessário refletir sobre a sua formação profissional e as práticas pedagógicas adotadas, pois a docência na universidade configura-se como um processo contínuo de construção da identidade docente, e tem por base os saberes da experiência, construídos no exercício profissional, mediante o ensino dos saberes específicos das áreas de conhecimento.

Nessa conjuntura, o método de ensino pela educação bancária como apresentado por Freire (1968) em sua obra Pedagogia do Oprimido, por mais que ainda seja um retrato de boa parte do sistema de transmissão de conteúdos de ensino no país, para os cursos de bacharelados, já não supre as necessidades do próprio perfil acadêmico-pedagógico desses cursos. 0 ensino na graduação atualmente está sendo mais dinâmico do que foi no fim do século XX e início do XXI.

Nessa ótica, é necessário um ensino para a graduação que dialogue a teoria e a prática de acordo com os estudos das suas áreas específicas frente às necessidades do mundo do trabalho, pois não há que se aceitar mais informações desconectadas com o que se passa nesse meio, estando apenas o docente dialogando ensaios e teorias outras que não convergem para o desempenho da função de um futuro profissional em pleno século XXI. Por isso, a importância da unidade teoria e prática. 
Na mesma direção, esse professor do magistério superior, deve estar conectado com as práticas pedagógicas, no sentido que a sua didática, seja aquela que colabora para o real aprendizado do aluno, seguindo uma estrutura disciplinar que externe seu conhecimento perante o assunto a ser trabalhado mediante a sua experiência profissional docente e técnica. Há que se levar em conta também a experiência do alunado, pois estes, em sua grande maioria, chegam do mercado de trabalho com suas vivências em alguma área do conhecimento, ou seja, há sempre um entendimento prévio, mesmo advindo do senso comum, acerca de algum princípio das ciências humanas, sociais aplicadas, exatas, etc. Então, indagamos, como trabalhar nessa nova fase?.

Esclarecemos que uma aula universitária não é palestra, um bate-papo, muito menos a simples transmissão de um conteúdo apenas. Uma aula universitária é cerceada de planejamento, técnicas de ensino, de um sistema de avaliação que demonstre os conhecimentos e as habilidades auferidas pelos discentes, que tenha uma boa didática, que seja participativa. Alunos que frequentam um curso de graduação na atualidade, o constroem juntos com seus pares: aluno-aluno, professor-aluno, aluno-professor-instituição.

Assim, este ensaio teórico é fruto de nossas experiências enquanto docente universitário ao completarmos 10 anos de exercício no magistério superior no ano de 2019, refletindo a transição do mercado enquanto profissional bacharel para a docência universitária, ao ponto em que chegamos à conclusão que há necessidade de projetos e programas formativos específicos para a profissão docente, pois a complexidade dos processos e práticas de ensino são próprias e específicas para o campo da formação humana e técnica, respectivamente.

A configuração do profissional bacharel-docente, traz um caráter ímpar ao modo em executar seu trabalho nas instituições de ensino superior, pois em sua formação inicial, não há disciplinas que contemplem a formação de professor como também o oriente em como ser professor. Nessa perspectiva, um profissional que se forma em um curso de bacharelado, por exemplo, não o faz para se tornar professor, mas sim, para ser um profissional em alguma área específica do bacharelado.

Dessa forma, questionamos, qual profissional é responsável pela sua formação? Qual ou quais processos formativos, um professor de um curso de bacharelado percorreu para que se tornasse apto ao exercício docente? Como ele se formou ou tornou-se professor? Teria ele participado de alguma formação contínua, ou simplesmente pelo fato de ser bacharel, já estaria habilitado para a docência? Ou até mesmo, cursou alguma especialização, ou a experiência simplesmente o fez? Indagamos ainda: há instituições com cursos específicos de formação pedagógica de professores universitários? Estas têm investido em processo de formação contínua para seu corpo docente.

A abordagem do desenvolvimento profissional que trazemos nesse estudo, é aquela que nos orienta a sempre estarmos em processos de formação, ou seja, ele não para. Diferente da formação continuada que tem início e fim, pois atende a uma demanda específica para um determinado tema, tempo e lugar de aplicação. Nesse ponto, é crucial para os professores-bacharéis a busca por um desenvolvimento profissional docente que atenda seus anseios aos anseios dos alunos rumo a uma educação desprovida de conhecimentos e/ou informações marginalizadas. 
Precisamos de um sistema educacional que integrem aos docentes a pesquisa, o ensino e a extensão. E ainda podemos dizer agora, que há necessidade de internacionalização do ensino também. De repente a integralidade das ações das disciplinas inter e transdisciplinares que há alguns anos já estão sendo praticadas pelas academias, pode convergir nessa interação que dialogamos de forma mais ativa e dinâmica nesse momento em que vivemos.

Fala-se de abordagem sistêmica e holística para os cursos de bacharelados e quando nos deparamos na significação dessa abordagem, muitas vezes ficamos sem respostas por fazermos dela um paradigma, ou um modismo talvez. Há muito tempo se sabe que o planejamento como uma das funções do trabalho profissional nos bastidores e estes, não são vistos. O que o palco apresenta é a execução do plano. Então, se deu certo ou errado, o mérito está no bastidor.

\section{METODOLOGIA}

Trabalhar como docente e profissional bacharel na atualidade é trabalhar em um mercado incerto, mas que traz desafios diários para serem superados. Entretanto, diante de tantas pesquisas, previsões de demandas, informações, fórmulas matemáticas e estatísticas, etc., não são de se estranhar que um profissional que detém informação ou um professor tenha em mãos os artifícios necessários para a condução de seu trabalho. A verdade é que ele os tem. A questão agora é saber se ele utiliza ou não esses artifícios de maneira coerente. Então, fazemos outra indagação: o que falta ao professor universitário bacharel em sua formação?

\section{DISCUSSÃO TEÓRICA}

\section{Docência Universitária em pauta}

Nossa reflexão se inicia com a indagação de Marques et al. (2015), quando questiona se é possível formar professores sem os saberes da pedagogia [...]. A relevância dos saberes da pedagogia no processo de formação inicial acadêmica de professores é questão crucial para o entendimento dessa prática de ensino. Assim, a docência é uma atividade pedagógica, que demanda de seus profissionais saberes específicos (do conteúdo ensinado) e saberes pedagógicos, considerando o ensino como atividade intencional, orientada à aprendizagem e ao desenvolvimento do indivíduo, vinculada a um projeto formativo.

A pedagogia, como ciência que tem como objeto de estudos o fenômeno educativo, possibilita aos docentes o estabelecimento de uma visão de totalidade, favorecendo a construção de leituras da realizada aguçadas por um olhar investigativo e a promoção de uma ação mais intencional (MARQUES et al., 2015). Nessa perspectiva, a docência é considerada como profissão.

[...] a docência implica a posse de um conjunto de saberes específicos, a passagem por processos institucionalizados de formação - responsáveis pela certificação, sem a qual não é possível atuar naquela profissão -, e a distinção de outros campos profissionais. Considerar - e defender - a docência como profissão implica assumir uma postura crítica em relação a programas e políticas que promovem o rebaixamento da qualidade da formação inicial, a contratação de professores leigos, sem formação para a profissão, a redução da autonomia profissional (reveladoras da concepção de que os docentes precisam ser tutelados, por serem incapazes de realizar sua tarefa de maneira satisfatória). Ser 
profissional significa ter autonomia para tomar decisões sobre o processo de ensinoaprendizagem (selecionar atividades, textos, formas de avaliação etc., à luz das demandas concretas), mas também assumir responsabilidades sobre sua ação e os resultados de aprendizagem que dela devem decorrer. Há, portanto, um conjunto de saberes específicos que se apresentam como necessários ao exercício da docência, e que conferem especificidade a essa profissão e ao professor como profissional.

Essas questões nos provocam a refletir sobre o papel da formação pedagógica no desenvolvimento profissional de um docente que atua no ensino superior. De fato, assumimos com essas inquietações a necessidade de reforçar que esse profissional tenha uma formação sólida para atuar com os dilemas da prática pedagógica no ensino superior. Reconhecemos, como Veiga (2006), a importância do processo formativo para a docência universitária, situando a indissociabilidade entre ensino, pesquisa e extensão. Essa indissociabilidade aponta para a atividade reflexiva e problematizadora do futuro profissional. Na perspectiva que argumentam Pimenta et al. (2014), compreendemos que

O desenvolvimento profissional dos professores tem constituído um objetivo de propostas educacionais que valorizam a formação docente não mais baseada na racionalidade técnica, que os considera meros executores de decisões alheias, mas numa perspectiva que reconhece sua capacidade de decidir. Ao confrontar suas ações cotidianas com as produções teóricas, impõe-se a revisão de suas práticas e das teorias que as informa, pesquisando a prática e produzindo novos conhecimentos para a teoria e a prática de ensinar [...].

Assim, a docência universitária se caracteriza pelo processo de ensino e aprendizagem de conteúdos voltados à formação humana e de profissionais para o mercado de trabalho, onde o conhecimento técnico e a experiência do professor somam atributos que, a princípio, habilita-o para a prática docente, como também a pós-graduação lato e stricto sensu.

Mas, de acordo com a legislação brasileira, Lei de Diretrizes e Base da Educação Nacional - LDBEN n.9.394/96 (BRASIL, 1996), o artigo 66 informa que, para atuar como professor universitário, este deve possuir cursos em nível de pós-graduação, prioritariamente em programas de mestrado e doutorado, como também menciona o notório saber quando reconhecido por universidade com curso de doutorado em área afim, suprindo a exigência do título acadêmico.

Destaca-se aqui a análise de Coimbra et al. (2015), ao afirmar que o referido artigo delimita o perfil de docente universitário, ou seja, prioritariamente com Mestrado e Doutorado. O termo prioritariamente não é uma exigência obrigatória, mas sabemos que tem sido exigido um percentual mínimo, nas avaliações dos cursos de graduação, realizadas pelo Ministério da Educação (MEC)ํ․ Entretanto, a referida lei, não menciona curso específico para a formação docente universitária, como exemplo, a Pedagogia Universitária².

Mediante os fatos, o contexto dos cursos de pós-graduação stricto sensu evidencia que não existe nenhum direcionamento específico para a formação docente para o ensino superior (COIMBRA et al., 2015), centrando-se no desenvolvimento de uma pesquisa que deve resultar uma dissertação ou tese. Entretanto,

\footnotetext{
${ }^{1}$ Espera-se que $75 \%$ ou mais docentes do curso de graduação tenham titulação obtida em programas de pós-graduação stricto sensu ou quando percentual de doutores do curso é maior que 35\% (Brasil, 2012 como citado em Coimbra \& Felício, 2015, p. 33).

2 Para conhecimento do projeto “Pedagogia Universitária” ver Relatório de Gestão 2006/2009 da Profa. Dra. Selma Garrido Pimenta - Pró-Reitoria de Graduação da USP.
} 
uma das possibilidades anunciadas tem sido a exigência do estágio de docência, apresentada pela CAPES, mediante a portaria $52 / 2002^{3}$, aos bolsistas de pós-graduação.

Ou seja, para os estudantes de mestrado e doutorado contemplados com bolsa de estudo, por esta instituição, é exigido o estágio de docência como requisito de manutenção ou de prestação de contas final da concessão da bolsa. É sob esse aspecto que os autores Pimenta et al. (2002) afirma que há preocupação sobre a formação docente universitária, indo além do conhecimento técnico, necessitando assim, de saberes pedagógicos.

A crescente preocupação com a docência no ensino superior tem proporcionado um aumento nos estudos sobre o tema da formação e do desenvolvimento profissional de seus professores, para além de um saber meramente técnico-disciplinar. Amplia-se a demanda desses profissionais por formação no campo dos saberes pedagógicos e políticos, o que indica um reconhecimento da sua importância para o ensinar bem.

\section{Formação Universitária do Professor Bacharel: a necessidade dos saberes didático-pedagógicos}

Para Coimbra et al. (2015), no cenário educacional contemporâneo, a formação do professor constitui-se como elemento fundamental para a qualidade da educação brasileira. Entretanto, as discussões e produções mais difundidas sobre esta temática têm como referência a formação de professores para a Educação Básica, desenvolvida no âmbito dos cursos de licenciaturas, e se mostra escassa quando se trata da formação desse profissional que atua no Ensino superior sem formação pedagógica.

Gonçalves (2015), por sua vez, afirma que quando discutimos o exercício da docência por profissionais sem formação pedagógica estamos abordando uma formação de professores em exercício, com poucos referenciais teóricos de docência em sua área de formação. Assim, “[...] a formação do educador necessita abranger o elemento técnico de especialização em uma área do saber (e a capacitação contínua), assim como a dimensão pedagógica da capacidade de ensinar; [...]" (CORTELLA, 2000). A essa capacidade de ensinar, apontamos agora o caráter técnico da didática para embasar nossas reflexões.

\footnotetext{
$\mathrm{Na}$ maioria das instituições brasileiras de ensino superior, incluindo as universidades, embora seus professores, ou parte deles, tenham realizado sua formação em cursos de pósgraduação stricto sensu e possuam experiência profissional significativa e até mesmo anos de estudos em suas áreas específicas, predomina o desconhecimento científico e até o despreparo para lidar com o processo de ensino-aprendizagem, pelo qual passam a ser responsáveis a partir do instante em que ingressam em na sala de aula. O panorama internacional não é diferente, como demonstra literatura específica. Porém, tanto aqui como em outros países tem havido crescente preocupação com a formação e o desenvolvimento profissional de professores do ensino superior e com as inovações no campo da atuação didática.
}

Estudos anteriores evidenciam a natureza essencial da didática na formação de professores para o ensino superior (AROEIRA et al., 2018; VEIGA et al., 2015; PIMENTA et al., 2014; LIBÂNEO, 2013; VEIGA, 2010, 2013; MASETTO, 1992, 1993, 1998, 2003, 2012; ALMEIDA, 2012; PIMENTA, 1993, 1999, 2005, 2010). Sendo o ensino, uma atividade característica do professor, ele é uma prática social complexa, carregada de conflitos de valor e que exige opções éticas e políticas (PIMENTA et al., 2014). 
Nesse contexto, o professor necessita de uma instrumentalização ao mesmo tempo teórica e técnica para que realize satisfatoriamente o trabalho docente, em condições de criar sua própria didática, ou seja, sua prática de ensino em situações didáticas específicas conforme o contexto social em que ele atue (LIBÂNEO, 2013). Nessa direção, Pimenta (1999) colabora, quando questiona e afirma a necessidade da formação de professores para a prática docente, repensando seu papel enquanto formador.

\begin{abstract}
Para quê professores numa sociedade que, há muito, superou não apenas a importância destes na formação das crianças e dos jovens, mas que também é muito mais ágil e eficaz em trabalhar as informações? E então, para quê formar professores? Contrapondo-me a essa corrente de desvalorização profissional do professor e às concepções que o consideram como simples técnico reprodutor de conhecimentos e/ou monitor de programas pré-elaborados, tenho investido na formação de professores entendendo que na sociedade contemporânea cada vez se torna mais necessário o seu trabalho enquanto mediação nos processos constitutivos da cidadania dos alunos, para o que concorre a superação do fracasso e das desigualdades escolares. O que, me parece, impõe a necessidade de repensar a formação de professores.
\end{abstract}

Conforme afirma Pimenta (1999), as pesquisas sobre a prática estão anunciando novos caminhos para a formação docente. Por isso, a docência, como as demais profissões, é historicamente construída - ou seja, constituídas em determinados momentos como respostas a determinadas necessidades postas pela sociedade. Há profissões que deixaram de existir. Há outras, hoje, que são recentes. É a dinâmica social que possibilita a emergência de profissões e requer que se modifiquem internamente para responderem a novas demandas. O que provoca alterações também no preparo para o exercício profissional (PIMENTA, 1993).

Nas questões referentes ao exercício profissional, Libâneo (2013) afirma que o trabalho docente é parte integrante do processo educativo mais global pelo qual os membros da sociedade são preparados para a participação na vida social. A educação - ou seja, a prática educativa - é um fenômeno social e universal, sendo uma atividade humana necessária à existência e ao funcionamento de todas as sociedades. Desta forma, o avançar no processo de docência e do desenvolvimento profissional, mediante a preparação pedagógica não se dará em separado de processos de desenvolvimento pessoal e Institucional: este é o desafio a ser hoje, considerado na docência do ensino superior (PIMENTA et al., 2014).

Mediante os desafios impostos pela docência do ensino superior, Pimenta (2005) afirma que nos últimos anos, tem desenvolvido o ensino de didática nos cursos de licenciatura e realizado pesquisas sobre formação inicial e contínua de professores. É a partir dessas experiências que expõe algumas reflexões, com o desafio de colaborar para a formação de professores. [...]. Nessa perspectiva, Libâneo (2013), afirma que a didática é uma matéria de integração: ela nutre dos conhecimentos e práticas desenvolvidos nas metodologias específicas e nas outras ciências pedagógicas para formular generalizações em torno de conhecimentos e tarefas docentes comuns e fundamentais ao processo de ensino.

Nesse sentido, a formação de professores em docência no ensino superior deve, na atualidade, ser revestida da prática pedagógica, pois, num contexto dinâmico que a sociedade vive em pleno século XXI, não há que se admitir a grande lacuna que a falta da didática ainda persegue a formação docente no ensino superior (PIMENTA, 2015).

O exercício da profissão de professor requer preparo. Ser professor não é tarefa simples. Entendemos que essa preparação se dá tanto ao nível da formação em instituições e cursos especializados, quanto no processo de exercício direto da atividade profissional nas escolas, 
nas associações profissionais, enfim, na prática do exercício profissional. Embora tendo funções específicas, essas instâncias da formação não são dissociadas. Os cursos de formação devem ter a prática profissional como ponto de partida e essa, por sua vez, deve se alimentar das reflexões realizadas nos cursos de formação.

É necessário pensar, então, um processo formativo que desenvolva o trabalho pedagógico dos professores universitários pautado em questões didáticas, que evidenciem o real desempenho acadêmico sobre os diálogos em sala de aula quando da exposição de ideias. É salutar que, os professores universitários, compreendam o seu papel como agentes de transformação sistêmica no processo de ensino e aprendizagem frente aos discentes. Nas palavras de Masetto (1993),

Entendemos por Didática uma reflexão sistemática sobre o processo de ensino que tem por objetivo a aprendizagem em uma situação formal (institucional) de educação, buscando alternativas para os problemas da prática pedagógica em sala de aula. Sala de aula vista como um espaço de convivência humana e de relações pedagógicas. Sala de aula como espaço-síntese da ação educativa do professor que integra e articula os conhecimentos teórico-científicos, os técnicos-práticos e os políticos-estruturais em função da realidade social brasileira.

A essa função da realidade social brasileira, a atividade didática deve permear a difusão do saber de modo objetivo, dinamizando suas ações em práticas concretas, fazendo com que o entendimento do assunto abordado, tenha destaque frente à sua receptividade. Nessa direção, Masetto (1993), de forma didática, argumenta que

Para os problemas da prática pedagógica desta sala de aula, a Didática busca alternativas que facilitem a aprendizagem, a partir das teorias e conhecimentos produzidos sobre o processo de ensino. Estas teorias se manifestarão adequadas à prática pedagógica se encaminharem os problemas apresentados ou deverão ser substituídas por outras que apresentem saídas para as questões concretas em pauta. Neste sentido, a Didática faz o papel de mediação entre as reflexões teóricas e a prática.

Aroeira (2018) informa que, nesse contexto, a Didática como área epistemológica tem como finalidade fundamentar os processos de ensino e aprendizagem. Constitui-se numa disciplina que contribui para a reflexão crítica em relação à prática pedagógica no processo de aprendizagem, assim como para a práxis docente, explicitando o que vai além dos muros da universidade. Pimenta (2012) explica que a Didática "[...] constitui área disciplinar, por excelência, na formação de professores, com potencial para ressignificar o processo de formação docente, concebendo-a como área da Pedagogia, que tem o ensino e a aprendizagem, historicamente, situados como objeto de preocupação".

Pimenta (2005) destaca, portanto, que, pesquisas recentes têm se voltado à análise da prática docente, indagando-se por que, nas práticas pedagógicas e nas organizações escolares, se praticam teorias outras que não necessariamente aquelas produzidas pelas recentes investigações das ciências da educação. Em decorrência, têm colocado em foco a formação dos professores - a inicial e a contínua. E a essa formação, a necessidade atual é estudar a didática como prática pedagógica nesse processo formativo.

\section{Em busca de uma identidade profissional: a autoformação docente e a Pedagogia Universitária}

No contexto atual, ao retratarmos o papel profissional docente de um bacharel, somos levados a refletir que no momento em que assumimos a condição de regentes de classe universitária, categoricamente assumimos o papel de professor em sua função generalizada. Dessa forma, assumimos a identidade 
'professor' como outra profissão no mesmo nível da formação bacharelada. Temos outra função nesse ofício: a de ensinar.

Nessa direção, Gonçalves (2015) aponta que se a exigência legal não garante a formação de profissionais para o exercício da docência sem o preparo pedagógico e se esses profissionais assumem esse papel, mister se faz identificar os caminhos por ele percorridos para formar-se docente ao mesmo tempo que exerce essa profissão.

Segundo Ishii et al. (2015), a autoformação docente é concebida como um processo complexo do sujeito, em seu contínuo processo de aprendizagem. Trata-se de uma aplicação em si mesmo junto às experiências profissionais, de modo a fazer reconsiderações sobre a prática e rever atitudes para compreender as dificuldades surgidas no decorrer da ação docente. A autoformação requer preparo ao docente que assume seu papel de protagonista no processo de aprendizagem, pois pelo movimento da açãoreflexão-ação, manifesta sua atitude ao buscar a especialidade da profissionalização da sua função, agora, como professor universitário.

É sabido que quando de seu ingresso na docência, o bacharel mobiliza seus conhecimentos de profissão para transformá-los em conhecimento de ensino (GONÇALVES, 2015), da mesma forma, ele pode realizar cursos de especialização lato sensu em didática/metodologia do ensino superior (o que em sua grade a oferta da disciplina de didática abrange um componente apenas de 40 a 60 horas na carga horária total do curso), como também jornadas pedagógicas realizadas pelas instituições de ensino a cada início do semestre letivo. Entretanto, isso é insuficiente quando se fala no desenvolvimento da formação profissional docente. Esta, por sua vez, deve ser contínua.

Pimenta (2010) nos aponta uma observação, entendendo que a democratização do ensino passa pelos professores, por sua formação, sua valorização profissional, suas condições de trabalho, as pesquisas têm apontado para a importância do investimento no seu desenvolvimento profissional. O que envolve formação inicial e contínua articulada a um processo de valorização identitária e profissional dos professores. Identidade que é epistemológica, ou seja, que reconhece a docência como um campo de conhecimentos específicos [...].

Nessa direção, [...], a docência constitui um campo específico de intervenção profissional na prática social. Assim, o desenvolvimento profissional dos professores tem se constituído em objetivo de políticas que valorizam a sua formação não mais baseada na racionalidade técnica, que os considera como mero executores de decisões alheias, mas numa perspectiva que considera sua capacidade de decidir. Essa valorização indica a centralidade que os professores hoje ocupam na definição e implementação de políticas de ensino. [...] conforme nos afirma Pimenta (2010).

Nesse contexto, a Pedagogia Universitária, como novo campo de estudos e pesquisas, está ganhando espaço nas investigações referentes ao seu protagonismo, enquanto área investigativa de políticas e ações institucionais, em prol do desenvolvimento de seus professores e da própria academia, no que toca as questões referentes à formação de professores para o exercício do magistério no ensino superior. 
As peculiaridades que constituem esse novo campo, necessitam ser vestidas e revestidas constantemente de práticas pedagógicas que, deem sentido à docência universitária, haja vista seu papel na formação humana e técnica para a sociedade e o mercado, indissociadas. Pensar na docência universitária apenas como dinamizadora de um saber técnico, já não supre mais as lacunas acadêmicas e mercantis, ainda mais quando por parte de alguns profissionais do magistério superior, se percebe problemas com a falta de didática, elaboração de planos disciplinares e curriculares, processos de avaliação e desempenho, entre outros. Nesse sentido, Benedito et al. (1995) colabora ao afirmar que

[...] o professor universitário aprende a sê-lo mediante um processo de socialização em parte intuitiva, autodidata ou [...] seguindo a rotina dos 'outros'. Isso se explica, sem dúvida, devido à inexistência de uma formação específica como professor universitário. Nesse processo, joga um papel mais ou menos importante sua própria experiência como aluno, o modelo de ensino que predomina no sistema universitário e as reações de seus alunos, embora não há que se descartar a capacidade autodidata do professorado. Mas ela é insuficiente.

Assim, não é qualquer um que pode ser professor. Por isso também não é qualquer professor que consegue fazer frente aos desafios impostos pelas atividades do magistério superior (PIMENTA, 2010). É preciso um professor que exerça uma docência da melhor qualidade. Segundo Pimenta et al. (2002), a crescente preocupação com a docência no ensino superior tem proporcionado um aumento nos estudos sobre o tema da formação e do desenvolvimento profissional de seus professores, para além de um saber meramente teórico-disciplinar. Amplia-se a demanda desses profissionais por formação no campo dos saberes pedagógicos e políticos, o que indica um reconhecimento de sua importância para o ensinar bem.

Dessa forma, o trabalho que algumas instituições de ensino superior estão desenvolvendo em favor do seu corpo docente, está criando uma cultura conscientizadora de que a qualidade nos serviços prestados por meio dos processos de ensino e aprendizagem está intimamente relacionada, às práticas pedagógicas de formação de professores, ou seja, estão pensando em uma pedagogia voltada para o ensino superior.

Portanto, para construir compreensões sobre a pedagogia universitária faz-se necessário ressignificar a docência, como expressão de uma profissão dotada de complexidade, articulada ao sentido que tem a universidade, como instituição social, considerada como manancial de produção de conhecimentos e de formação humana. Não se trata de uma categoria específica de teoria pedagógica, mas de sistematizar conhecimentos a respeito da universidade, da formação docente-discente, da docência, dos estudantes, dos processos de ensino-aprendizagem em contexto, das políticas educacionais nos níveis macro e micro. Esse prisma implica examinar os condicionantes sociais, políticos, econômicos e culturais, assim como as relações que se estabelecem em seu interior e com a comunidade na qual está inserida, considerando as questões relativas à cultura, ao saber, à produção e disseminação do conhecimento.

\section{CONSIDERAÇÕES FINAIS}

Diante das exposições e diálogos que aqui trouxemos, destacamos o quanto está em evidência no contexto atual, as reflexões referentes à formação do professor universitário para o pleno desenvolvimento da sua carreira profissional docente. O paradigma constante que ainda afeta muitos profissionais bacharéis em sua função formativa no mercado e no magistério do ensino superior, como sendo o papel de não assumir a docência como profissão efetivamente exercida, deve a partir dos modelos de ensino e gestão atual, se 
modificar, ao passo que a revolução tecnológica se aproxima e como apresentamos, a forma de ensinar e aprender estão mudando.

As organizações como sistemas abertos interagem com o meio externo, fazendo a dinâmica das suas funções terem vida própria e nessa cadeia acíclica, está presente o profissional bacharel com sua habilidade técnica para o exercício da sua função formativa também. Nessa direção, somos sabedores que esse mesmo profissional, por sua vez, é o professor que está à frente da formação discente nos cursos de bacharelados concentrados no país e estes, carecem sim, de preparo profissional por meio de programas de desenvolvimento que articulem as questões referentes aos saberes pedagógicos, principalmente quanto aos de caráter didáticos.

A necessidade se faz presente mediante o quadro atual e panorâmico do país e do mundo, onde aspectos como empreendedorismo e liderança ganharam mais espaços nos debates nas aulas universitárias dos cursos de bacharelados. Assim, o papel docente em conduzir em sua totalidade esses debates de forma a fazer seus discentes pensarem de modo inovador, faz com que esse mesmo docente tenha consciência de seu papel frente a toda essa mudança.

Nesse aspecto, cabem as instituições de ensino superior, pensarem em políticas que reverberem programas de formação contínua para o seu corpo docente. Do mesmo modo, o professor em sua carreira profissional docente tem o dever de autoformar-se, pois se uma das funções de um profissional é o exercício do planejamento, da mesma forma, a busca pelo seu próprio desenvolvimento profissional deve ser constante.

Nessa experiência docente, ao caminharmos de profissional bacharel a profissional professor, coadunamos com os diálogos teóricos e estudos frente à importância e necessidade da formação docente diante do papel que exercemos ao entrarmos em uma sala acadêmica. Nosso papel não se traduz apenas a apresentarmos resultados técnicos, estes são importantes também, mas primeiramente nosso papel está na formação humana.

\section{REFERÊNCIAS}

ALMEIDA, M. I.. Formação do Professor do Ensino Superior: desafios e políticas institucionais. São Paulo: Cortez, 2012.

AROEIRA, K. P.. A didática e os estágios em licenciaturas: uma articulação necessária na produção de práticas pedagógicas. In: PIMENTA, S. G.; AROEIRA, K. P.. Didática e Estágio. Curitiba: Appris, 2018.

AROEIRA, K. P.; PIMENTA, S. G.. Didática e Estágio. Curitiba: Appris, 2018.

BENEDITO, A. V.; FERRER, V.; FERRERES, V.. La formación universitaria a debate. Barcelona: UB, 1995.

BRASIL. Lei n.9394 de 20 de dezembro de 1996. Estabelece as Diretrizes e Bases da Educação Nacional. Brasília: DOU, 1996.

BRASIL. Portaria n.52 de $\mathbf{2 6}$ de setembro de 2002. Aprova o novo Regulamento do Programa de Demanda Social. Brasília: DOU, 2002.
COIMBRA, C. L.; FELÍCIO, H. M. S.. Formação do Docente Universitário: estatuto legal, políticas e perspectivas atuais. In: COIMBRA, C. L.; MONIZ, M. I. A. S.; ARAMOWICZ, M.; STANO, R. C. M. T.; GONÇALVES, Y. P.. A construção do saber docente por bacharéis no ensino superior: desafios de uma formação. Curitiba: CRV, 2015.

CORTELLA, M. S.. A escola e o conhecimento: fundamentos epistemológicos e políticos. São Paulo: Cortez, 2000.

FRAGELLI, C. M.; CARRASCO, L. B. Z.; AZEVEDO, M. A. R.. A formação do professor universitário: aspectos históricos e explorações futuras. In: SEMINÁRIO INTERNACIONAL DE EDUCAÇÃO SUPERIOR, FORMAÇÃO E CONHECIMENTO. Anais. Sorocaba: 2014.

FREIRE, P.. Pedagogia do Oprimido. São Paulo: Paz e Terra, 1968. 
GONÇALVES, A. M.; PERES, S. M.. Educação básica e continuada de professores: modelos, problemas conceituais, ações e condições histórico-político-institucionais. Revista do Centro de Ensino Superior de Catalão, v.4, n.6, 2002.

GONÇALVES, Y. P.. Construindo a pesquisa: razões e fundamentos. In: COIMBRA, C. L.; MONIZ, M. I. A. S.; ARAMOWICZ, M.; STANO, R. C. M. T.; GONÇALVES, Y. P.. A construção do saber docente por bacharéis no ensino superior: desafios de uma formação. Curitiba: CRV, 2015.

ISHII, A. B. F.; MONIZ, M. I. A. S.. A autoformação dos docentes do ensino superior: caminhos flagrados. In: COIMBRA, C. L.; MONIZ, M. I. A. S.; ARAMOWICZ, M.; STANO, R. C. M. T.; GONÇALVES, Y. P.. A construção do saber docente por bacharéis no ensino superior: desafios de uma formação. Curitiba: CRV, 2015.

LIBÂNEO, J. C.. Didática. 2 ed.. São Paulo: Cortez, 2013. MARQUES, A. C. T. L.; PIMENTA, S. G.. É possível formar professores sem os saberes da pedagogia? Uma reflexão sobre docência e saberes. Revista Metalinguagens, v.3, p.135-156, 2015.

MASETTO, M. T.. Aulas Vivas: tese e prática de livre docência. São Paulo: 1992.

MASETTO, M. T.. Didática e a formação de professor de 3o grau. Revista da Faculdade de Educação, São Paulo, v.19, n.1, p.132-134, 1993.

MASETTO, M. T.. Docência na universidade. Campinas: Papirus, 1998.

MASETTO, M. T.. Docência universitária: repensando a aula. In: TEODORO, A.; VASCONCELOS, M. L.. Ensinar e aprender no ensino superior: por uma epistemologia da curiosidade da formação universitária. 3 ed. São Paulo: Cortez, 2003. p.79-108.

MASETTO, M. T... Competência Pedagógica do Professor Universitário. 2 ed. São Paulo: Summus, 2012.

MELO, G. F.. Pedagogia Universitária: aprender a profissão, profissionalizar a docência. Curitiba: CRV, 2018.

PIMENTA, S. G.. A didática na licenciatura. Revista da Faculdade de Educação, São Paulo. v.19, n.1, p.128-132, 1993.

PIMENTA, S. G.. Didática: embates contemporâneos. São Paulo: Loyola, 2010.
PIMENTA, S. G.. Formação de professores: identidade e saberes da docência. In: PIMENTA, S. G.. Saberes pedagógicos e atividade docente. São Paulo: Cortez, 1999. p.15-34.

PIMENTA, S. G.. Formação de Professores: identidades e saberes na docência. In: PIMENTA, S. G.. Saberes pedagógicos e atividade docente. 4 ed. São Paulo: Cortez, 2005.

PIMENTA, S. G.. Formação e Profissionalização docente. São Paulo: UNISANTOS, 2015.

PIMENTA, S. G.. Professor Reflexivo: construindo uma crítica. In: PIMENTA, S. G.; GHEDIN, E.. Professor Reflexivo no Brasil: gênese e crítica de um conceito. 7 ed. São Paulo: Cortez, 2012. p.20-62.

PIMENTA, S. G.. Relatório de Gestão 2006/2009. São Paulo: USP, 2009.

PIMENTA, S. G.; ANASTASIOU, L. G. C.. A Docência no Ensino Superior. São Paulo: Cortez, 2014.

PIMENTA, S. G.; ANASTASIOU, L. G. C.; CAVALLET, V. J.. Docência no Ensino Superior: Construindo Caminhos. In SEVERINO, A. J.; FAZENDA, I. C. A.. Formação Docente: Rupturas e Possibilidades. Campinas: Papirus, 2002.

PIMENTA, S. G.; GHEDIN, E.. Professor Reflexivo no Brasil: gênese e crítica de um conceito. 7 ed. São Paulo: Cortez, 2012.

VEIGA, I. P. A.. A prática pedagógica do professor de didática. Campinas: Papirus Editora, 2013.

VEIGA, I. P. A.. Alternativas pedagógicas para a formação do professor da educação superior. In: VEIGA, I. P. A.; VIANA, C. M. Q. Q.. Docentes para a educação superior: processos formativos. Campinas: Papirus, 2010.

VEIGA, I. P. A.. Docência Universitária na Educação Superior. Docência na educação superior. In: RISTOFF, D.; SEVEGNANI, P.. Brasília: INEP, 2006.

VEIGA, I. P. A.; SILVA, E. F.; XAVIER, O. S.; FERNANDES, R. C. A.. Pós-Graduação: espaço de formação pedagógica de docentes para a educação superior. In: VEIGA, I. P. A.; DÁVILA, C. M.. Didática e docência na educação superior: implicações para a formação de professores. Campinas: Papirus, 2015.

A CBPC - Companhia Brasileira de Produção Científica (CNPJ: 11.221.422/0001-03) detém os direitos materiais desta publicação. Os direitos referem-se à publicação do trabalho em qualquer parte do mundo, incluindo os direitos às renovações, expansões e disseminações da contribuição, bem como outros direitos subsidiários. Todos os trabalhos publicados eletronicamente poderão posteriormente ser publicados em coletâneas impressas sob coordenação da Sustenere Publishing, da Companhia Brasileira de Produção Científica e seus parceiros autorizados. Os (as) autores (as) preservam os direitos autorais, mas não têm permissão para a publicação da contribuição em outro meio, impresso ou digital, em português ou em tradução. 